\title{
AN INTERESTING CASE OF SEROTONIN SYNDROME
}

\section{DEVANG J. BARAD ${ }^{1 *}$, R VEDAMANICKAM ${ }^{2}$, SARANYA DEVI K ${ }^{3}$}

1: Junior Resident, Department of General Medicine, Sree Balaji Medical College and Hospital, Chrompet, Chennai-600044

2: Professor, Department of General Medicine, Sree Balaji Medical College and Hospital, Chrompet, Chennai-600044

3: Assistant Professor, Department of General Medicine, Sree Balaji Medical College and Hospital, Chrompet, Chennai-600044

*Corresponding Author: Dr. Devang J. Barad: E Mail id: devangbarad@yahoo.com

Received 23 ${ }^{\text {rd }}$ March. 2021; Revised 24 ${ }^{\text {th }}$ April 2021; Accepted 20 ${ }^{\text {th }}$ May 2021; Available online $1^{\text {st }}$ Dec. 2021 https://doi.org/10.31032/IJBPAS/2021/10.12.5783

\begin{abstract}
Serotonin Syndrome (SS) may occur in patients on serotonin agonist medications. Milder form of SS is often unrecognized due to non-specificity of symptoms. Co-administration of two or more proserotonergic drugs makes the patient of even more susceptible for developing SS. We wish to report a case of SS in an elderly female with anxiety disorder who developed SS upon intake of commonly used opioid analgesic. Most important point is careful history taking and knowledge of the drugs causing SS, which helps to diagnose the condition in time.
\end{abstract}

Keywords: Serotonin syndrome, Tramadol, Proserotonergicdrugs, Cyproheptadine INTRODUCTION

Tramadol is one of the most commonly used analgesics. Serotonin Syndrome (SS) secondary to tramadol ingestion might have a higher incidence, but is often unrecognized, may be, because of lower severity of symptoms in mild cases, non-specificity of symptoms and rampant use of the drug as an analgesic [1, 2].

\section{CASE REPORT}

A 54 years old female patient was brought to emergency room with complaints of anxiety, agitation, sweating, shivering, nausea and 
loose stools since last 3 hours. There was no history of fever, abdominal pain, burning micturition, chest pain, palpitation, orthopnea, headache, blurring of vision, trauma or seizure episode. There was no history of ingestion of outside Food. There was no history of any panic event or family quarrel. Patient is a known case of anxiety disorder for the past 5 years and it is on Tab. Escitalopram $10 \mathrm{mg}$ HS for it. No other comorbidities were present. Patient is married since last 30 years and has two children. She attained menopause 5 years ago. There was no history of any addictions or allergies. On examination, patient was conscious, oriented, restless and agitated. Shivering was present. Vitally, temperature was $99.8^{\circ} \mathrm{F}$, pulse was $110 / \mathrm{min}$. (regular), BP was $140 / 90 \mathrm{mmHg}$, RR was 24/min., $\mathrm{SPO} 2$ was $98 \%$ on room air. There was no pallor,icterus, cyanosis, clubbing,edema, or lymphadenopathy. Systemic examination was unremarkable except for exaggerated superficial reflexes. A provisional diagnosis of panic episode was made and patient was treated with IV fluids, antiemetic, $\mathrm{H}_{2-}$ blocker, and benzodiazepine (IV diazepam 5 mg stat). There was some improvement in symptoms after 1 hour of treatment, but the complaints of nausea and loose stools still persisted.Upon investigation, CBC, RFT with
S. electrolytes, LFT and RBS were within normal limits. ABG showed metabolic alkalosis. ECG showed sinus tachycardia with no ST-T changes or bundle branch block.Chest X-ray was normal. Due to persistence of symptoms, history was again reviewed by asenior consultant which revealed consumption of 2 doses of OTC formulation of Tramadol and Paracetamol for lower backache around 8 hours before the onset of symptoms. In view of development of serotonergic symptoms following the addition of an opioid analgesic with concomitant intake of a SSRI, presumptive diagnosis of serotonin syndrome was made based on Hunter Serotonin Toxicity Criteria. All the SSRI and opioid analgesic were stopped. Conservative treatment was continued and Tab. Cyproheptadine was added. Over the next 24 hours, the symptoms subsided. The patient was discharged after 48 hoursupon normalization of heart rate and was referred back to psychiatry department for review of medications.

\section{DISCUSSION}

Serotonin Syndrome (SS) occurs as a result of a state of serotonin excess at synaptic and peripheral receptors, and most commonly occurs due to the synergistic effect of two or more proserotonergic drugs $[\mathbf{1}, \mathbf{2}]$. It is mostly a diagnosis of exclusion [3] and the 
spectrum of clinical features may vary from simple tremors and loose stools to severe muscle rigidity and hyperthermia. Other differential diagnoses for serotonin syndrome are Neuroleptic Malignant Syndrome (NMS), Malignant Hyperthermia, anticholinergic toxicity, heat stroke and meningitis. Careful History taking and knowledge of the drugs causing SS often helps in clinching the diagnosis. Hunter Serotonin Toxicity Criterion has good sensitivity and specificity in diagnosing the condition[4]. As with the clinical features, treatment also ranges simply from administration of a benzodiazepine and an antipyretic in milder cases to sedation with muscle paralysis in severe cases. Cyproheptadine, a serotonin receptor antagonist, is an important drug to alleviate the symptoms [5].

\section{CONCLUSION}

Serotonin Syndrome (SS), in its milder form, is often missed as an initial diagnosis. Careful history taking and knowledge of the drugs causing it often helps to clinch the diagnosis in time.

\section{REFERENCES}

[1] Jacqueline Volpi-Abadie, Adam M. Kaye, Alan David Kaye Ochsner J. 2013 Winter; 13(4): 533-540. PMCID: PMC3865832
[2] Swati Jindal, Satinder Gomba, Kompal Jain Serotonin Syndrome in ICU-A Road Less Traveled Indian Journal of Critical Care Medicine (2019): 10.5005/jp-journals-1007123222

[3] Pedavally S, Fugate J, Rabinstein A. Serotonin Syndrome in the Intensive Care Unit: Clinical Presentations and Precipitating Medications. Neurocritical Care 2013; 21: 108113.

[4] Cooper B, Sejnowski C. Serotonin Syndrome. AACN AdvCrit Care 2013; 24: 15-20.

[5] Boyer, E. and Shannon, M. The Serotonin Syndrome. N Engl J Med 2005; 352: 1112-1120. 